\title{
A sustainable process for gram-scale synthesis of stereoselective aryl substituted $(E)$-2-thiocyanatoacrylic acids
}

\author{
RAJAN ABRAHAM and PRAKASH PERIAKARUPPAN* (D) \\ Department of Chemistry, Thiagarajar College, Madurai, Tamil Nadu 625 009, India \\ E-mail:kmpprakash@gmail.com
}

MS received 21 August 2017; revised 7 December 2017; accepted 11 December 2017; published online 7 February 2018

\begin{abstract}
We have developed a new, simple and sustainable process for stereoselective synthesis of aryl substituted $(E)$-2-thiocyanatoacrylic acids by nucleophilic substitution and Knoevenagel condensation involving chloroacetic acid, ammonium thiocyanate and aromatic aldehydes at room temperature. The selectivity was controlled by appropriately choosing aromatic aldehydes. The influence of intramolecular hydrogen bonding of 3-(2-hydroxyphenyl)-2-thiocyanatoacrylic acid involves the formation $(Z)$ isomers. The salient features of the present protocol are mild reaction conditions, excellent yield, easy filtration, clean reaction profiles and applicability towards gram-scale synthesis. Importantly, the synthetic application of this protocol leads to the emergence of various biologically important compounds.
\end{abstract}

Keywords. (E)-2-thiocyanatoacrylic acids; Knoevenagel condensation; stereoselective synthesis; gram-scale synthesis.

\section{Introduction}

The formation of carbon-sulfur bond constitutes a key reaction in biosynthetic processes as well as in organic synthesis. ${ }^{1}$ Sulfur-containing molecules are ranked top among the most imperative motifs in natural and biologically important compounds (Figure 1). ${ }^{2-8}$ Due to the development of milder and safer access to the thiocyanates, it is obvious that a larger scientific community will be attracted by this multitasking functional group. Particularly, these species act as the building blocks for many heterocyclic or organosulfur compounds. ${ }^{9}$ For example, thiocyanates are used as precursors to other sulfur-based functional groups such as thiols, thioethers, disulfides, isothiocyanates and phosphonothioates. In addition, thiocyanates act as pseudohalides and cyanating agents. They show a wide range of biological activities such as anticancer agents, ${ }^{10}$ antioxidants, ${ }^{11}$ pro-inflammatory activity, ${ }^{12}$ anti-inflammatory and anti-microbial effects. ${ }^{13}$ This functional group serves as a precursor to the preparation of many pharmaceutical compounds including agrochemicals, drugs and dyes. ${ }^{14-16}$ Furthermore, thiocyanates can readily be

\footnotetext{
*For correspondence
}

transformed into a more versatile sulfur-bearing group for the additional structure modification. ${ }^{17-20}$

Acrylic acid derivatives are key intermediates for the synthesis of various biologically important compounds. ${ }^{21}$ Generally, aryl acrylic acids and their amides have potent inhibitory activity as well as good antioxidant and anti-inflammatory activities. ${ }^{22}$ Due to their great importance, development of a novel synthetic approach for the preparation of aryl substituted -2thiocyanatoacrylic acid derivatives is attempted herein. A new synthetic route for this valuable scaffold is reported via nucleophilic substitution (C-S bond formation) and Knoevenagel condensation ( $\mathrm{C}-\mathrm{C}$ bond formation). Generally, the Knoevenagel condensation of aldehydes with an active methylene compound is one of the classical methods for carbon-carbon ${ }^{23}$ bond formation in organic synthesis.

Since 1898, Knoevenagel condensation has been showing several advantages like reaction simplicity, mild conditions, and application in synthesizing biologically privileged compounds which have made it an active field of research among organic chemists. ${ }^{24}$ Commonly, many researchers have used Knoevenagel condensation by involving various aldehydes with different active methylene compounds such as Meldrum's 


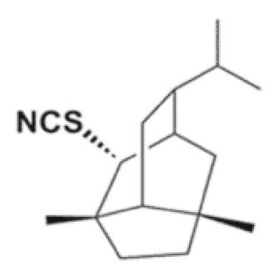

9-thiocyanato pupukeanane

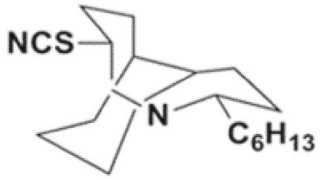

fasicularin<smiles>N#CCCNC(=O)/C(Cc1ccc(O)c(Br)c1)=N\O</smiles><smiles>N#SCc1ccc(Cl)cc1Cl</smiles><smiles>[R]c1cc(-c2noc(C[As])n2)cc([R])c1[R2]</smiles><smiles>[R]c1ccc(-c2nc3sc(Cc4ccccc4)nn3c2[Si]#N)cc1</smiles><smiles>[R]n1cc([As])c2ccccc21</smiles>

$\mathrm{R}=\mathrm{H}, \mathrm{Cl}, \mathrm{OMe}$

$\mathrm{R}=\mathrm{Ph}, \mathrm{N}-$ Methylated 2(4-dichloroPhenyl)

Figure 1. Bioactive thiocyanate-containing natural products.

acid, dimedone, barbituric acid, malononitrile, cyanoacetamide, acetylacetone, ethylacetoacetate, ethyl cyanoacetate and cyanoacetic acid (Figure $2 \mathrm{a}-\mathrm{i}$ ). ${ }^{25-31}$ While all these types of active methylene compounds provide access to Knoevenagel products, there are certain limitations associated with them such as the use of hazardous bases, harsh reaction conditions, tedious workup procedures and selectivity. Therefore, we aim to develop a mild, efficient and selectivity-controlled approach with new active methylene compound to produce highly desired Knoevenagel products. In the present study, we describe the development of a practical process for the gram-scale synthesis of streoselective aryl substituted (E)-2-thiocyanatoacrylic acids involving chloroacetic acid, ammonium thiocyanate, aromatic aldehydes and ammonium acetate at room temperature (Scheme 1).

Notably, in this newly developed protocol, $\mathrm{NH}_{4} \mathrm{SCN}$ acts as a source of -SCN and is used to combine with chloroacetic acid to make a new compound containing active methylene group (2-thiocyanatoacetic acid). This gram-scale synthetic process will certainly be highly beneficial for industrial purposes and practical process in the organic laboratory.

\section{Experimental}

\subsection{Materials and physical measurements}

All the chemicals are commercially available and purchased from Sigma-Aldrich or Merck and used as received. The ${ }^{1} \mathrm{H}$,
${ }^{13} \mathrm{C}$ NMR spectra were recorded on a Bruker (Avance) 400 and $500 \mathrm{MHz}$ NMR instrument using DMSO- $\mathrm{d}_{6}$ as solvent. The standard Bruker software was used throughout. Chemical shifts are reported in parts per million (ppm, $\delta$ units) and coupling constants are given in hertz. Thin layer chromatography (TLC) was run on the silica gel-coated aluminium sheets and glass plates (silica gel 60 GF254, E. Merck, Germany) and visualized in iodine chamber and confirmed under UV light $(254 \mathrm{~nm})$. ESI-HRMS spectra were recorded on Bruker Maxis 10138 mass spectrometer.

\subsection{General procedure for compound $\mathbf{2}$}

A mixture of chloroacetic acid (1.5 equiv.) and ammonium thiocyanate (1.5 equiv.) in $5 / 5 \mathrm{~mL}$ of acetonitrile/methanol were taken and stirred well for $15 \mathrm{~min}$ at room temperature. Then, aromatic aldehyde ( 1 equiv.) and ammonium acetate (1.5 equiv.) were added to the reaction mixture and this reaction was continued for $12 \mathrm{~h}$. After completion of the reaction, it was monitored in TLC and then the reaction mixture was poured into the $400 \mathrm{~mL}$ cold water. The formed precipitate of products were filtered by simple filtration and washed with water to obtain the crude product. The crude product was recrystallized by using absolute ethanol to get pure product 2 .

\section{Results and Discussion}

We began initially the reaction of chloroacetic acid, $\mathrm{NH}_{4} \mathrm{SCN}$ and aldehyde 1 in $\mathrm{CH}_{3} \mathrm{CN}$ at room temperature. The reaction mixture in the absence of a base did not yield the desired product $\mathbf{2}$ and only thiocyanation reaction took place with the yield of $98 \%$ of 2-thiocyanatoacetic acid (3) (Table 1, entry 1). 


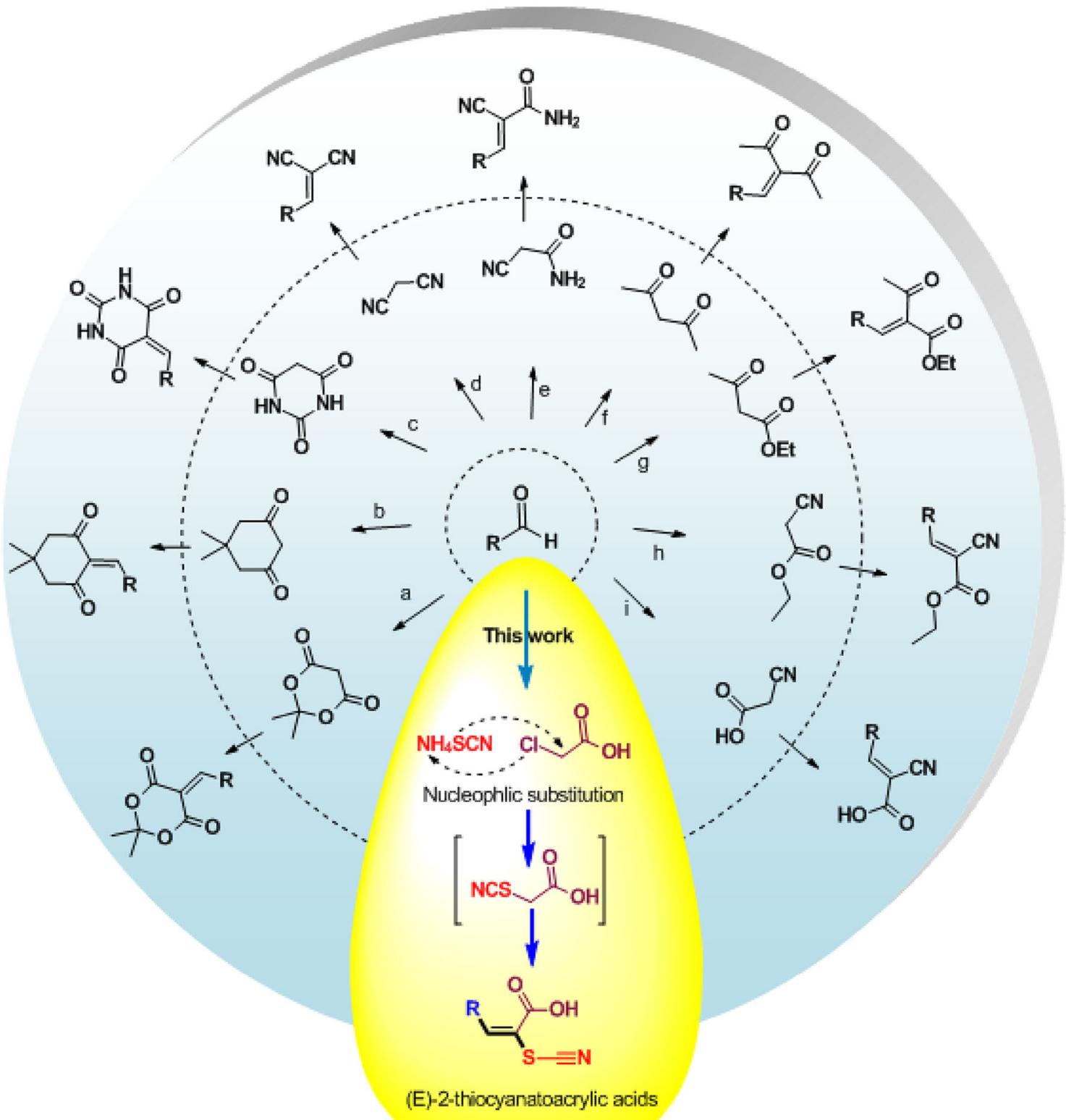

Figure 2. Different active methylene groups involved in the formation Knoevenagel products.

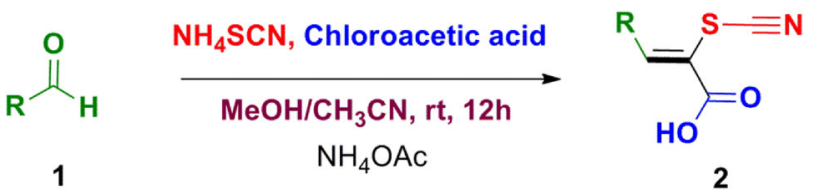

Scheme 1. Synthetic route for the 2-thiocyanatoacrylic acid derivatives 2 .

Then the active methylene protons of $\mathbf{3}$ got activated when the reaction mixture under a basic condition with several organic and inorganic bases were investigated. Among the organic bases, $\mathrm{Et}_{3} \mathrm{~N}$ produced a moderate yield of desired product $2(58 \%$, Table 1 , entry
2). Whereas inorganic bases like $\mathrm{NH}_{3}$ and $\mathrm{NH}_{4} \mathrm{OAc}$ improved the yield of the desired product 2 , respectively, to $67 \%$ and $75 \%$ (Table 1, entries 2 and 3), yet these conversions were unsatisfactory. Next, various solvents such as THF, EtOH and $\mathrm{MeOH}$ were tested and screened for the desired product 2 (Table 1, entry 4-6). Finally, the synthesis of aryl substituted 2-thiocyanatoacryclic acid derivative reactions could be achieved efficiently at room temperature with an excellent yield (99\%, Table 1, entry 8) in mixed solvents such as $\mathrm{CH}_{3} \mathrm{CN}-\mathrm{MeOH}(\mathrm{v} / \mathrm{v}$ $=1: 1$ ).

Table 2 shows the formation of selectivity-controlled products of $E$-isomers of 2-thiocyanatoacryclic acid 
Table 1. Optimization of the reaction conditions for the synthesis of aryl substituted 2-thiocyanatoacrylic acid derivatives.

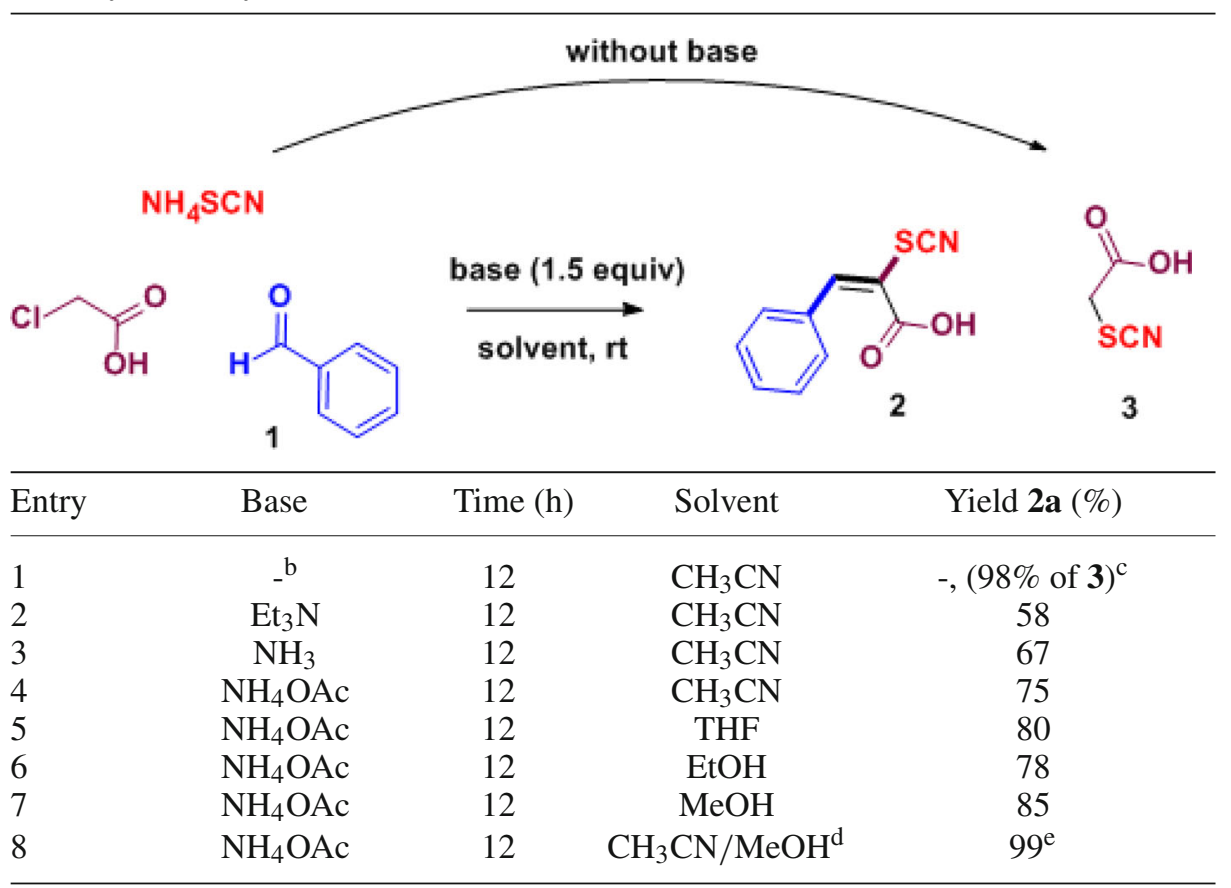

${ }^{a}$ Reaction conditions: chloroacetic acid, ammoniumthiocyanate and aromatic aldehyde at room temperature for $12 \mathrm{~h} .{ }^{b}$ without base. ${ }^{c}$ only active methylene compound $\mathbf{3}$ formation. ${ }^{d}$ mixture of solvents. ${ }^{e}$ excellent conversion yield.

Table 2. Selectivity controlled synthesis of aryl substituted-2-thiocyanatoacrylic acids from appropriately chosen aromatic aldehydes.

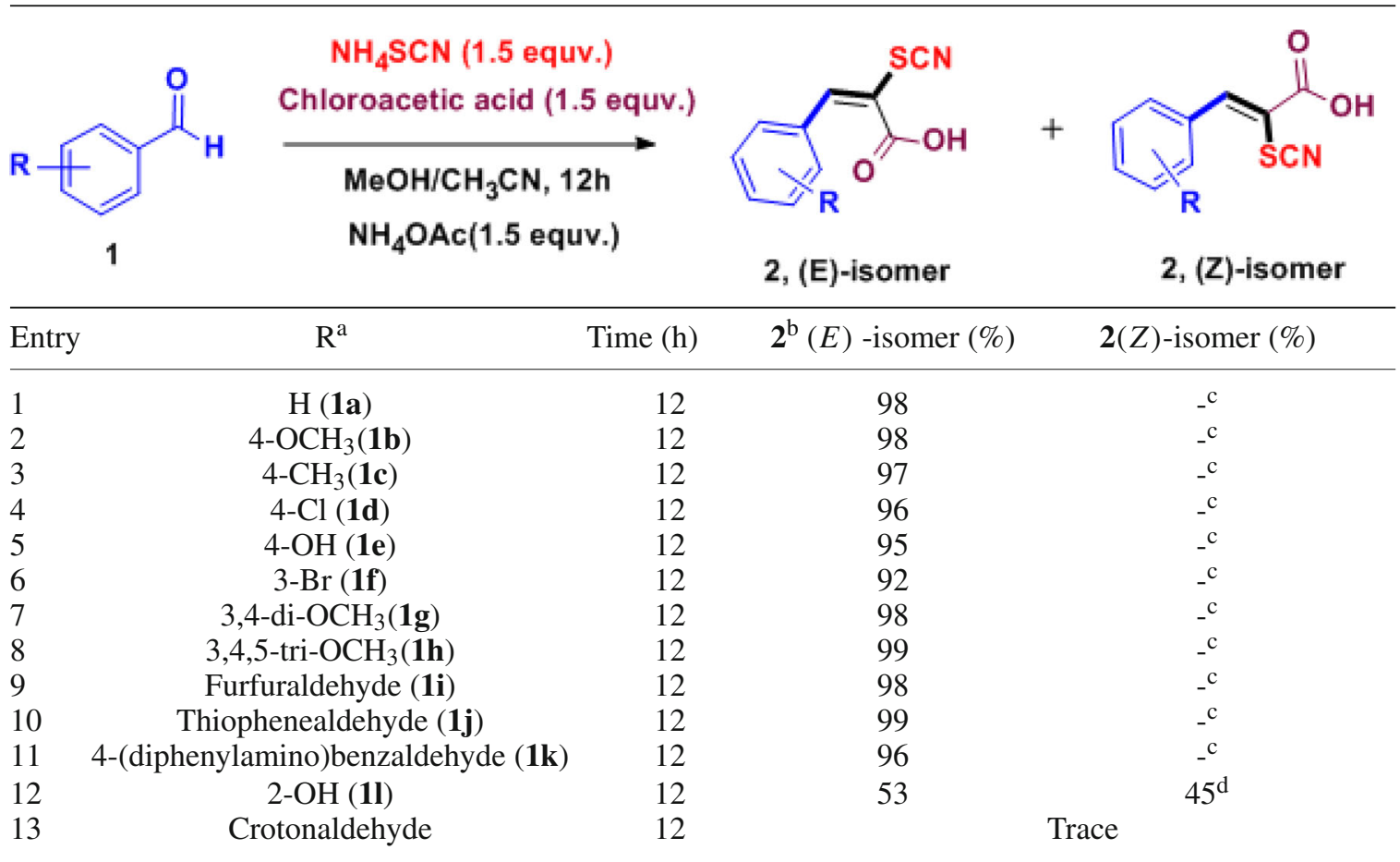

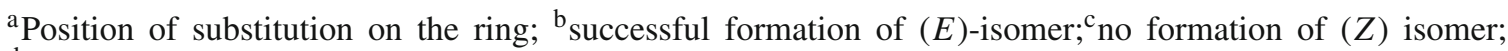
${ }^{d}$ formation of $(Z)$-isomer. 


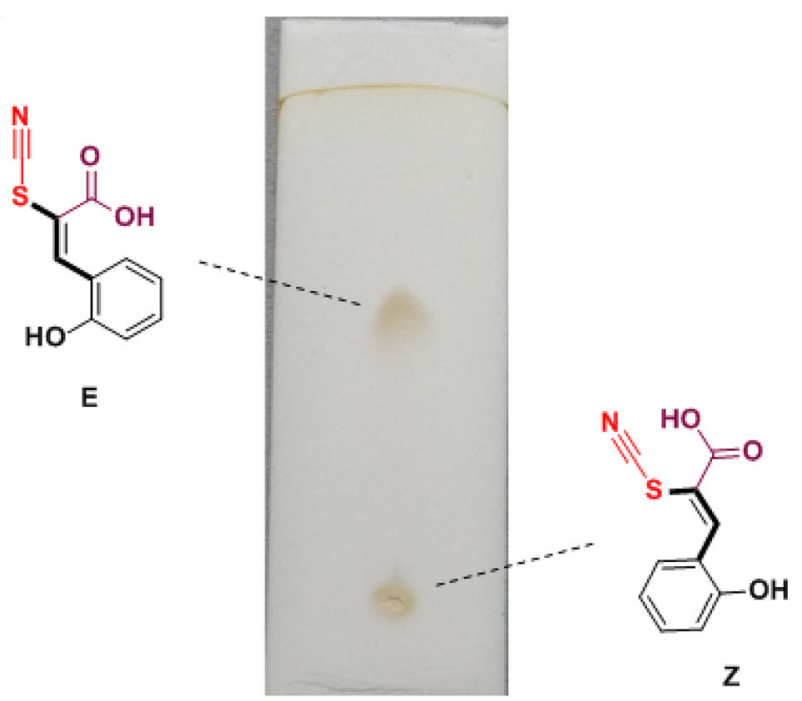

Figure 3. Photographic image of (E)- and (Z)-3-(2-hydroxyphenyl)-2-thiocyanatoacrylic acid isomers on TLC (25\% ethyl acetate with hexane elution).

derivatives from chloroacetic acid, $\mathrm{NH}_{4} \mathrm{SCN}$, aromatic aldehydes in the presence of $\mathrm{NH}_{4} \mathrm{OAc}$ in $\mathrm{CH}_{3} \mathrm{CN}$ $\mathrm{MeOH}$ mixture solvent. Firstly, un-substituted aromatic aldehyde was examined. Benzaldehyde (1a) gave an excellent yield of $E$-isomer (Table 2, entry 1). Among the various substituted aldehydes tested, 4-substituted aldehydes (1b-1e) produced almost $95-98 \%$ yield of the desired $E$-isomer, $\mathbf{2 b}-\mathbf{e}$ (Table 2, entry 2-5). 3bromo substituted benzaldehyde (1f), 3,4-di- (1g) and 3,4,5-trimethoxy substituted benzaldehyde (1h) were also found to produce good yields of $E$-isomer (Table 2, entries 6-8). Similarly, the hetero aromatic aldehydes (1i and $\mathbf{1 j}$ ) gave higher yields of $E$-isomer (Table 2, entry 9 and 10). 4-(diphenylamino)benzaldehyde (1k) was tested and gave $96 \%$ of $(E)$-2-thiocyanatoacrylic acid (Table 2, entry 11$)$. But both $(E) \&(Z)$ isomers were obtained from 2-hydroxy benzaldehyde (11) (Table 2, entry 12). Then an aliphatic unsaturated aldehyde (crotonaldehyde $(\mathbf{1 m})$ ) was also tested but only a trace amount of yield was obtained (Table 2, entry 13). The formation of both $E$ and $Z$ isomers may be attributed to the influence of intramolecular hydrogen bonding. ${ }^{32}$ The $(E)-\&(Z)-3-(2-h y d r o x y p h e n y l)-2-$ thiocyanatoacrylic acid (2i) isomers were easily separated out which could be visualized by naked eye through TLC (Figure 3).

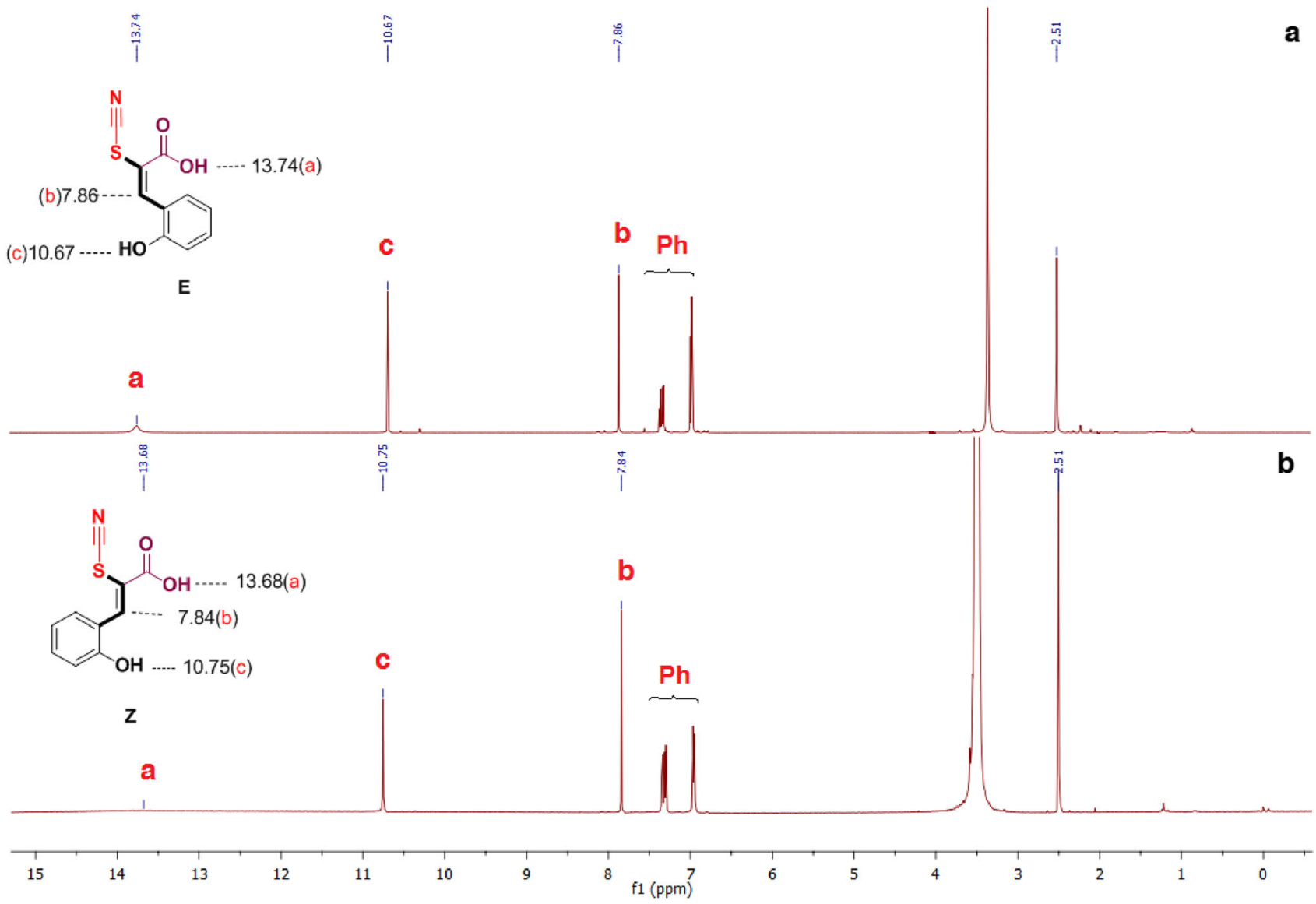

Figure 4. ${ }^{1} \mathrm{H}-\mathrm{NMR}$ (DMSO-d ${ }_{6}$ ) Spectra. (a) $E$-isomer and (b) Z-isomer of 3-(2-hydroxyphenyl)-2-thiocyanatoacrylic acid showing intramolecular hydrogen bonding effect. 


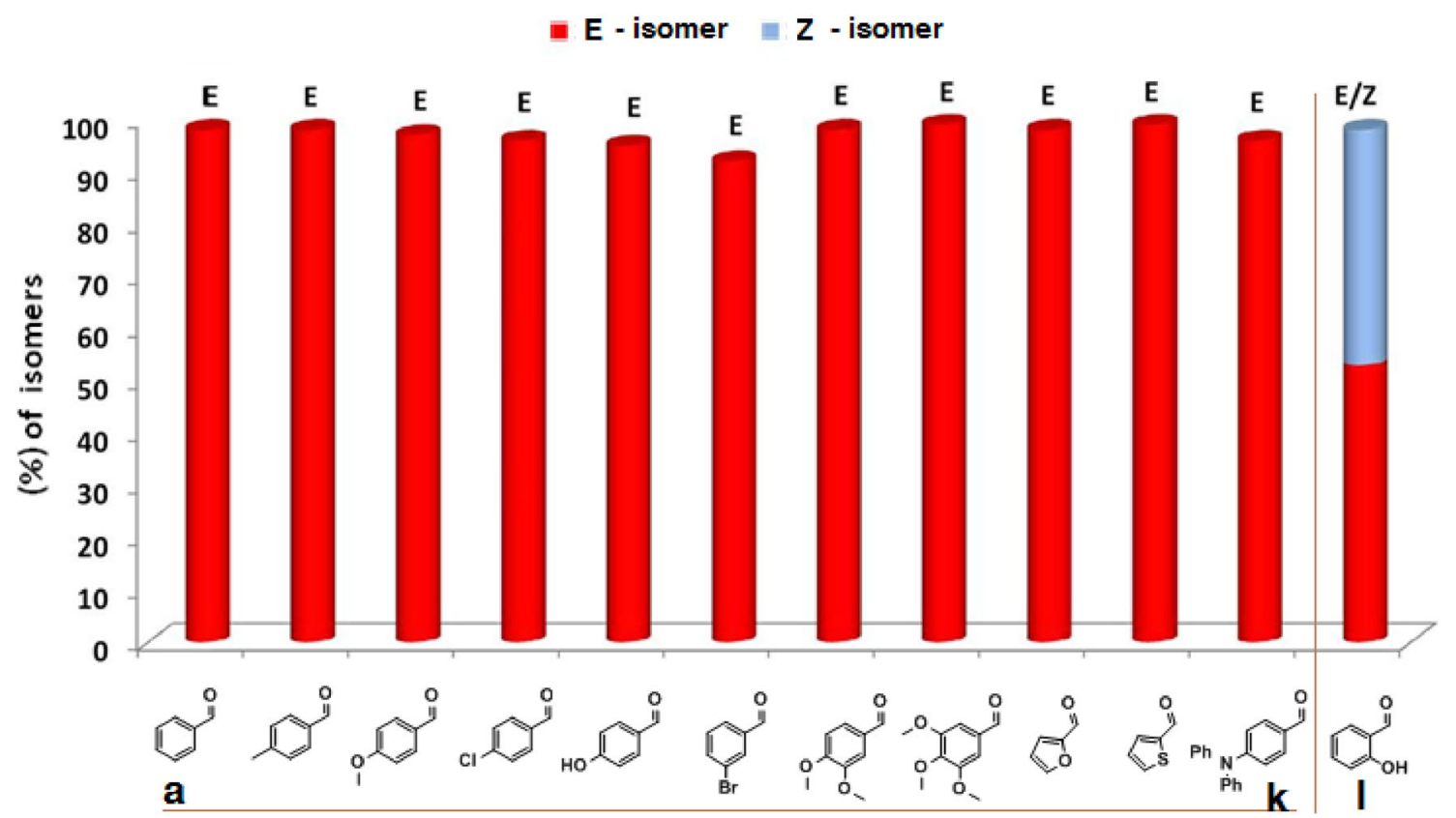

Figure 5. Selectivity controlled synthesis of aryl substituted (E)-2-thiocyanatoacrylic acids.

Further, the isomers were separated individually by column chromatography (eluant hexane: ethyl acetate) and the intramolecular hydrogen bonding was identified with peaks shifts from low to high region in ${ }^{1} \mathrm{H}-\mathrm{NMR}$ spectrum of $(E) \&(Z)$ isomers which was indicated by the difference of $-\mathrm{OH}(0.08 \mathrm{ppm})$ and $\mathrm{COOH}(0.01 \mathrm{ppm})$ peaks as shown in Figure 4. The substituted aldehydes (1a-1k) formed only the $(E)$ 2-thiocyanatoacrylic acids which was confirmed by (in addition to NMR analysis (videESI)) TLC plates showing only one spot (figure not shown) when compared to 2-hydroxy benzaldehyde (11) (Figure 3).

From the Figure 5, it can be clearly seen that the selectivity could be achieved in the formation of aryl substituted 2-thiocyanatoacrylic acids by proper selection of aromatic aldehydes, viz unsubstituted, 4substituted, 3-substituted, 3,4-disubstituted and 3,4,5-tri substituted which give only $E$-isomers (Figure 5ak). But 2-OH benzaldehyde gives both the isomeric products $(E \& Z)$ due to the intramolecular hydrogen bonding (Figure 5 l).

With the optimized conditions in hand (Table 1, entry 8), the substrate scope of the present study with respect to various aromatic and hetero aromatic aldehydes were evaluated and the results are summarized in Scheme 2. Both electron donating groups (EDGs) and electron withdrawing groups (EWGs) on phenyl rings of the aldehydes give the corresponding desired aryl substituted (E)-2-thiocyanatoacrylic acids (Scheme 2, $\mathbf{2 a - 2 h )}$ in good yields. In the case of five membered heterocyclic aldehydes such as furfuraldehyde and thiophenealdehyde, the products were obtained in $98 \%$ and $99 \%$ yields respectively (Scheme 2, 2i and $\mathbf{2 j}$ ). Furthermore, 4-(diphenylamino)benzaldehyde effectively react under the optimized reaction conditions and give the corresponding $(E)$-2-thiocyanatoacrylic acids $\mathbf{2 k}$ in $96 \%$ yield. But, hydroxyl group in the second position on benzaldehyde generates the $(E) \&(Z)$-2thiocyanatoacrylic acids (2l) with 45 and $58 \%$ yields, respectively.

We then extended the work for the gram-scale synthesis of $\mathbf{2 h}$ under the optimized conditions. Pleasingly, (E)-2-thiocyanato-3-(3,4,5-trimethoxyphenyl)

acrylic acid (2h) was obtained in an excellent yield (99\%) which was conducted on a gram scale process (Figure S1 in Supplementary Information), which indicates that there is a potential for practical methods in organic laboratory and industrial applications too.

The plausible mechanism for the formation of aryl substituted 2-thiocyanatoacrylic acid is depicted in Scheme 3. First, the nucleophilic substitution reaction of thiocyanate ion $\left(\mathrm{SCN}^{-}\right)$with the $\alpha$ carbon of chloroacetic acid takes place to form a 2-thiocyanatoacetic acid, 3 . Then, 3 interacts with ammonium acetate to produce the ammonium 2-thiocyanatoacetate salt $\mathbf{4}$ which was activated by ammonium acetate abstracting a proton from the methylene group of $\mathbf{4}$. Then, 4 undergoes Knoeveneagel condensation with protonated aldehyde to form $\mathbf{5}$ which was neutralized by water to afford the product 2. 
<smiles>[R]C=O</smiles><smiles>COC(=O)C(C)C(C)C</smiles><smiles>[R]C=C([As])C(=O)O</smiles><smiles>N#CS/C(=C/c1ccccc1)C(=O)O</smiles><smiles>COc1ccc(/C=C(\SC#N)C(=O)O)cc1</smiles><smiles>Cc1ccc(C=C(SC#N)C(=O)O)cc1</smiles>

2a, $98 \%$

$2 b, 98 \%$

2c, $97 \%$<smiles>N#CS/C(=C/c1ccc(Cl)cc1)C(=O)O</smiles>

$2 d, 96 \%$<smiles>COc1ccc(/C=C(/SC#N)C(=O)O)cc1OC</smiles>

$2 \mathrm{~g}, 98 \%$<smiles>N#CS/C(=C/c1ccc(O)cc1)C(=O)O</smiles>

$2 e, 95 \%$<smiles>COc1cc(/C=C(/SC#N)C(=O)O)cc(OC)c1OC</smiles>

$2 \mathrm{~h}, 99 \%$<smiles>N#CS/C(=C/c1cccc(Br)c1)C(=O)O</smiles>

$2 f, 92 \%$<smiles>N#CS/C(=C/c1cccs1)C(=O)O</smiles>

$2 \mathrm{j}, 99 \%$<smiles>N#CS/C(=C/c1ccc(N(c2ccccc2)c2ccccc2)cc1)C(=O)O</smiles><smiles>N#CS/C(=C/c1ccccc1O)C(=O)O</smiles><smiles>N#CS/C(=C\c1ccccc1O)C(=O)O</smiles>

(E), $21,53 \%$

(Z), 2I, 45\%

Scheme 2. Synthesis of aryl substituted (E)-2-thiocyanatoacrylic acids 2. 


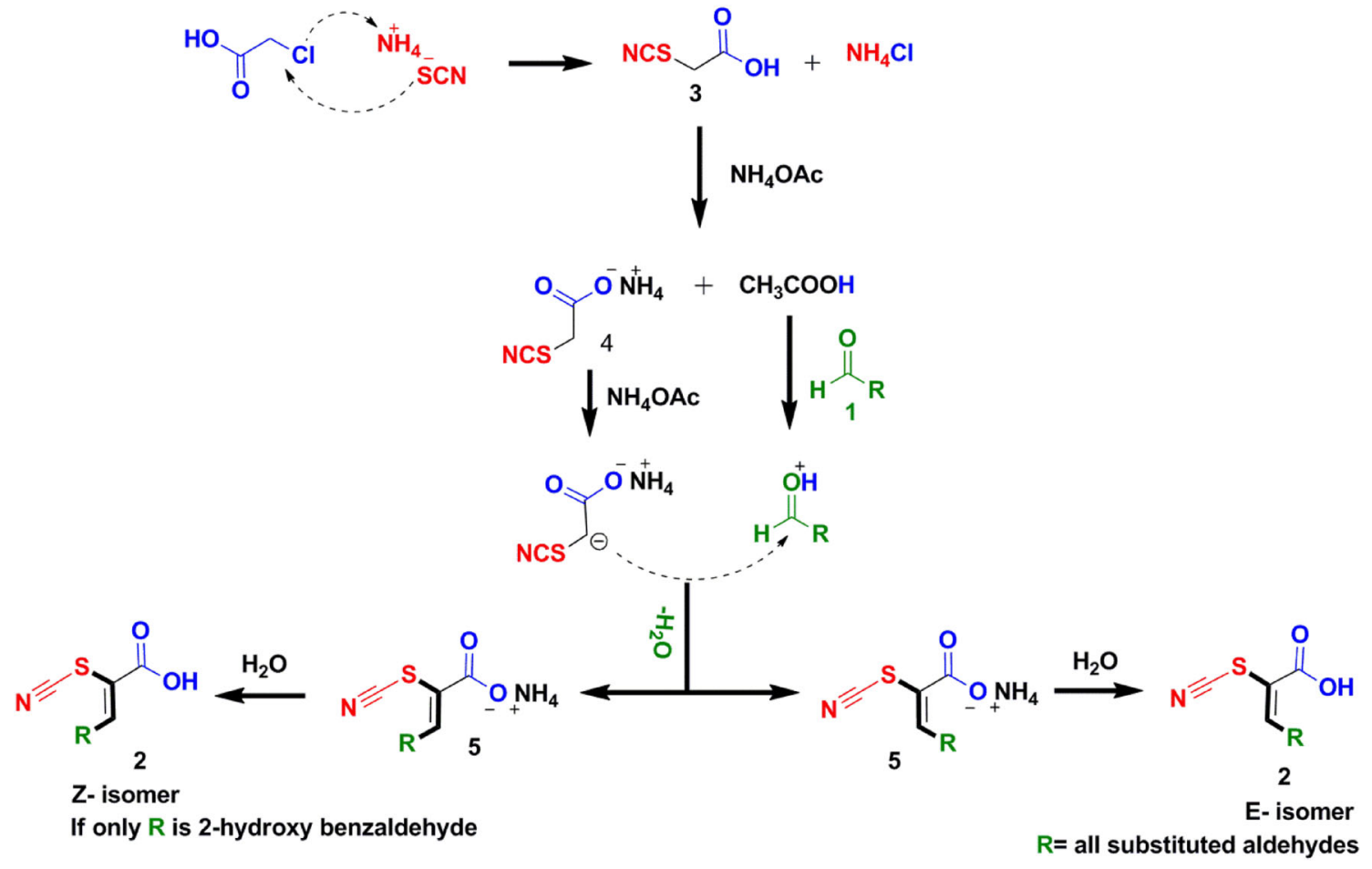

Scheme 3. Plausible mechanism for the synthesis of $(E)$ - and (Z)-2-thiocyanatoacrylic acids.

\section{Conclusions}

In summary, we have achieved a novel, mild and efficient method for the selective synthesis of aryl substituted (E)-2-thiocyantoacrylic acids from easily available starting materials in very good yields. The selectivity was controlled by the selection of appropriate aromatic aldehydes. Furthermore, the advantages of this method are the selectivity control, mild reaction conditions, excellent yields, operational simplicity, absence of tedious separation procedures, easy handling, clean reaction profiles and energy efficiency. The current methodology with mild reaction conditions and operational simplicity offers a method for gram-scale synthesis and applicability to practical processes in organic laboratory and industry.

\section{Supplementary Information (SI)}

The spectral data and copies of ${ }^{1} \mathrm{H},{ }^{13} \mathrm{C}$ NMR and HRMS of all the compounds are given in the Supplementary Information which is available at www.ias.ac.in/chemsci.

\section{Acknowledgements}

Support and spectra for this work were obtained at the UGC Networking Resource Centre, School of Chemistry, University of Hyderabad, Telangana, India.

\section{References}

1. (a) Clark J H 1980 Fluoride ion as a base in organic synthesis Chem. Rev. 80 429; (b) Fujita E and Nagao Y J 1977 Tumor inhibitors having potential for interaction with mercapto enzymes and/or coenzymes: A review. Bioorg. Chem. 6 287; (c) Trost B M and Keeley D E 1975 New synthetic methods. Secoalkylative approach to grandisol. J. Org. Chem. 40 2013; (d) Shono T, Matsumura Y, Kashimura S and Hatanaka K 1979 Onestep joining reaction of thiolate anions, activated olefins, and carbonyl compounds J. Am. Chem. Soc. 101 4752; (e) Nishimura K, Ono M, Nagaoka Y and Tomioka K 1997 Steric Tuning of Reactivity and Enantioselectivity in Addition of Thiophenol to Enoates Catalyzed by an External Chiral Ligand J. Am. Chem. Soc. 11912974

2. Zhao P, Yin H, Gao H and Xi C 2013 Cu-Catalyzed Synthesis of Diaryl Thioethers and S-Cycles by Reaction of Aryl Iodides with Carbon Disulfide in the Presence of DBU J. Org. Chem. 785006

3. Artico M, Silvestri R, Pagnozzi E, Bruno B, Novellino E, Greco G, Massa S, Ettorre A, Loi A G, Scintu F and Colla P L 2000 Structure-Based Design, Synthesis, and Biological Evaluation of Novel Pyrrolyl Aryl Sulfones: HIV-1 Non-Nucleoside Reverse Transcriptase Inhibitors Active at Nanomolar Concentrations J. Med. Chem. $\mathbf{4 3}$ 1886

4. Beletskaya I P and Ananikov V P 2011 Transition-MetalCatalyzed C-S, C-Se, and C-Te Bond Formation via Cross-Coupling and Atom-Economic Addition Reactions Chem. Rev. 1111596

5. (a) Cottrell D M, Capers J, Salem M M, Fradley K D, Croft S L and Werbovetz K A 2004 Antikinetoplastid activity of 3-aryl-5-thiocyanatomethyl-1,2,4oxadiazoles Bioorg. Med. Chem. 12 2815; (b) Havens C 
G, Bryant N, Asher L, Lamoreaux L, Perfetto S, Brendle $\mathrm{J}$ and Werbovetz K 2000 Cellular effects of leishmanial tubulin inhibitors on L. donovani Mol. Biochem. Parasitol. 110223

6. (a) Bai R-L, Duanmu C and Hamel E 1989 Mechanism of action of the antimitotic drug 2,4-dichlorobenzyl thiocyanate: alkylation of sulfhydryl groups of ß-tubulin Biochim. Biophys. Acta 994 12; (b) Saarivirta M 1973 The formation of benzylcyanide, benzylthiocyanate, benzylisothiocyanate and benzylamine from benzylglucosinolate in lepidium Planta. Med. 24112

7. Kumar S, Gopalakrishnan V, Hegde M, Rana V, Dhepe S S, Ramareddy S A, Leoni A, Locatelli A, Morigi R, Rambaldi M, Srivastava M, Raghavan S C and Karki S S 2014 Synthesis and antiproliferative activity of imidazo[2,1b] $[1,3,4]$ thiadiazole derivatives Bioorg. Med. Chem. Lett. 244682

8. Margiani P F, Paulo B N S, Teresinha G S, Teodoro S K, Gardenia C G M and Claudio S 2016 Synthesis and preliminary evaluation of 3-thiocyanato-1H-indoles as potential anticancer agents Eur. J. Medi. Chem. 11821

9. Castanheiro T, Suffert J, Donnard M and Gulea M 2016 Recent advances in the chemistry of organic thiocyanates Chem. Soc. Rev. 45494

10. Mehta R G, Liu J, Constantinou A, Thomas C F, Hawthorne M, You M, Gerhüser C, Pezzuto J M, Moon R C and Moriarty R M 1995 Cancer chemopreventive activity of brassinin, a phytoalexin from cabbage Carsinogenesis 16399

11. Chandler J D and Day B J 2012 THIOCYANATE: A potentially useful therapeutic agent with host defense and antioxidant properties Biochem. Pharmacol. 84 1381

12. Whitehouse M W and Jones M 2009 Pro-inflammatory activity in rats of thiocyanate, a metabolite of the hydrocyanic acid inhaled from tobacco smoke Inflamm. Res. 58693

13. Chandler J D, Min E, Huang J, McElroy C S, Dickerhof N, Mocatta T, Fletcher A A, Evans C M, Liang L, Patel M, Kettle A J, Nichols D P and Day B J 2015 Antiinflammatory and Antimicrobial Effects of Thiocyanate in a Cystic Fibrosis Mouse Model Am. J. Respir Cell. Mol. Biol. 53193

14. MacKinnon D L and Farrell A P 1992 The effect of 2-(Thiocyanomethylthio)benzothiazole on juvenile coho salmon (Oncorhynchus Kisutch ): Sublethal toxicity testing Environ. Toxicol. Chem. 111541

15. Falck J R, Gao S, Prasad R N and Koduru S R 2008 Electrophilic $\alpha$-thiocyanation of chiral and achiral $\mathrm{N}$ acyl imides. A convenient route to 5-substituted and 5,5-disubstituted 2,4-thiazolidinediones Bioorg. Med. Chem. Lett. 181768

16. Aoyama $\mathrm{T}$, Murata $\mathrm{S}$, Takido $\mathrm{T}$ and Kodomari $\mathrm{M}$ 2007 Novel one-pot three-step reaction using supported reagents system: synthesis of 2-aminothiazoles Tetrahedron 6311933

17. Lee Y T, Choi S Y and Chung Y K 2007 Microwaveassisted palladium-catalyzed regioselective cyanothiolation of alkynes with thiocyanates Tetrahedron Lett. 48 5673
18. Zhang Z and Liebeskind L S 2006 PalladiumCatalyzed, Copper(I)-Mediated Coupling of Boronic Acids and Benzylthiocyanate. A Cyanide-Free Cyanation of Boronic Acids Org. Lett. 84331

19. Billard T, Langlois B R and Médebielle M 2001 Tetrakis(dimethylamino)ethylene (TDAE) mediated addition of difluoromethyl anions to heteroaryl thiocyanates. A new simple access to heteroaryl-SCF2R derivatives Tetrahedron Lett. 423463

20. Riemschneider R, Wojahn F and Orlick G 1951 Thiocarbamates. III. Aryl Thiocarbamates from Aryl Thiocyanates J. Am. Chem. Soc. 735905

21. Ong A L, Kamaruddin A H and Bhatia S 2005 Current technologies for the production of (S)-ketoprofen: Process perspective Process Biochem. 403526

22. Pontiki E, Hadjipavlou-Litina D, Litinas K, Nicolotti O and Carotti A 2011 Design, synthesis and pharmacobiological evaluation of novel acrylic acid derivatives acting as lipoxygenase and cyclooxygenase- 1 inhibitors with antioxidant and anti-inflammatory activities Eur. J. Medi. Chem. 46191

23. (a) Jones G 1967 In Organic Reactions Wiley 15 204; (b) L F Tietze, U Beifuss, B M Trost and I Fleming (Eds.) 1991 Comprehensive Organic Synthesis (Oxford: Pergamon Press) p. 341

24. Knoevenagel E 1898 Condensationen zwischen Malonester und Aldehyden unter dem Einfluss von Ammoniak und organischen Aminen Ber. Dtsch. Chem. Ges. 31

25. Brahmachari G 2015 Room Temperature One-Pot Green Synthesis of Coumarin-3-carboxylic Acids in Water: A Practical Method for the Large-Scale Synthesis ACS Sustainable Chem. Eng. 32350

26. Reeve A M 2015 Reaction of Dimedone and Benzaldehyde: A Discovery-Based Lab for Second-Semester Organic Chemistry J. Chem. Educ. 92582

27. Panja S K, Dwivedia N and Saha S 2015 First report of the application of simple molecular complexes as organocatalysts for Knoevenagel condensation $R S C A d v .5$ 65526

28. Schneider E M, Zeltner M, Kränzlin N, Grass R N and Stark W J 2015 Base-free Knoevenagel condensation catalyzed by copper metal surfaces Chem. Commun. 51 10695

29. Kalita S J, Mecadon H and Deka D C 2014 Reaction of 6-aminouracils with aldehydes in water as both solvent and reactant under $\mathrm{FeCl} 3 \cdot 6 \mathrm{H} 2 \mathrm{O}$ catalysis: towards 5-alkyl/arylidenebarbituric acids $R S C A d v .4$ 32207

30. Tejada R P, Baroja N M D, Franco S, Pelleja L, Ordun J, Andreu R and Garin J 2015 Organic sensitizers bearing a trialkylsilyl ether group for liquid dye sensitized solar cells Dyes Pigments 123293

31. Ding Y, Ni X, Gu M, Li S, Huang H and Hu Y 2015 Knoevenagel condensation of aromatic aldehydes with active methylene compounds catalyzed by lipoprotein lipase Catal. Commun. 64101

32. Ikegami M and Arai T 2005 Effect of the Intramolecular Hydrogen Bonding on the Photochromic Properties of the Hemiindigo Dye having a Pyrrole Ring Mol. Cryst. Liq. Cryst. $\mathbf{4 3 1} 445$ 